\title{
Can positron emission tomography help stratify the risk of sudden cardiac death in patients with hypertrophic cardiomyopathy?
}

\author{
G. Neal Kay, MD \\ a Division of Cardiovascular Disease, Department of Medicine, University of Alabama at \\ Birmingham, Birmingham, AL
}

Received May 4, 2018; accepted May 4, 2018

doi: $10.1007 / \mathrm{s} 12350-018-1299-3$

\section{See related article, pp. 1125-1134}

Hypertrophic cardiomyopathy (HCM) is a heterogeneous cardiac disease based on autosomal genetic mutations of genes coding for proteins involving the sarcomeres and myofilament elements. ${ }^{1-4}$ The clinical consequences of these mutations are widely variable, ranging from patients remaining totally asymptomatic to the most dreaded outcome, sudden cardiac death (SCD) which accounts for over $50 \%$ of deaths in this population. ${ }^{4}$ Despite considerable advances in our understanding of the genetic basis for this disease and its relation to the clinical course of patients with these mutations, ${ }^{5}$ there remains considerable heterogeneity in the risk of adverse outcomes. This is especially relevant as a clinician tries to prevent sudden cardiac death for an individual patient while minimizing the burden of therapy. ${ }^{6}$

The only established therapy to prevent sudden cardiac death in patients with HCM is the implantable cardioverter-defibrillator (ICD). ${ }^{7-9}$ The generally accepted indications for prevention of SCD with an ICD in HCM are based on recognized risk factors, including a prior history of ventricular fibrillation or sustained ventricular tachycardia, maximum LV wall thickness $\geq 30 \mathrm{~mm},{ }^{10} \mathrm{SCD}$ in a first degree relative with $\mathrm{HCM}^{11}{ }^{11}$ unexplained syncope within the past 6 months, ${ }^{12}$ nonsustained VT (especially if $>150$

Reprint requests: G. Neal Kay, MD, Division of Cardiovascular Disease, Department of Medicine, University of Alabama at Birmingham, Birmingham, AL; nealkay@hotmail.com

J Nucl Cardiol 2019;26:1135-7.

1071-3581/\$34.00

Copyright (C) 2018 American Society of Nuclear Cardiology. bpm), ${ }^{13}$ or an abnormal blood pressure response to exercise (failure to increase systolic pressure $>20 \mathrm{~mm}$ $\mathrm{Hg}$. ${ }^{1,2,6,7,9,11,14}$ The risk of lethal arrhythmic events is higher for patients presenting with HCM in childhood, ${ }^{5}$ those having Troponin I or T mutations, ${ }^{5}$ and those with higher serum BNP concentrations. ${ }^{15}$ The positive and negative predictive values of any one of these clinical risk factors to predict SCD have been relatively poor. ${ }^{5,6}$ In addition, for continuous variables such as $\mathrm{LV}$ wall thickness, the risk of SCD increases in a curvilinear manner, making a clear cut-off value that is "safe" all but impossible to establish. ${ }^{16}$ Potential clinical features that increase the risk of SCD include younger age ( $<30$ years), LV outflow tract obstruction, ${ }^{17}$ a remote history of syncope, the presence of epicardial coronary artery disease, end-diastolic LV cavity dimension, ${ }^{1}$ left atrial diameter, ${ }^{12}$ and the presence of an LV aneurysm. ${ }^{17}$ And yet, despite identification of these clinical features which have been well documented to increase the risk of $\mathrm{SCD}$, even low-risk patients may experience this tragic outcome. $^{4,6}$ The prevention of SCD is made more challenging by the fact that living with an ICD can be a significant burden to patients, including the risk of inappropriate shocks, lead malfunction, and requirement for pulse generator replacement. ${ }^{8}$ Because of this, any technique that can reduce the need for ICD implantation in patients who are truly at low risk of SCD would be of high clinical value. ${ }^{18}$

A welcome addition to risk assessment for patients with HCM has been the identification of late gadolinium enhancement (LGE) on cardiac MRI as an independent predictor of SCD. ${ }^{19-24}$ Compared with HCM patients without LGE, the adjusted SCD event risk increases continuously with the extent of LGE. For each $10 \%$ increase in the extent of LGE, the risk of SCD increased by a hazard ratio of $1.46 .^{21}$ An important observation has been that in patients with HCM who were considered to be at low risk for SCD by conventional clinical 
measures, the extent of LGE was able to identify patients who subsequently suffered SCD. ${ }^{22}$ Among 429 patients with HCM without LGE, SCD occurred in 5 $(1.2 \%) .^{22}$ Nevertheless, among the 37 patients with HCM suffering a potentially lethal ventricular arrhythmia, $11(29.8 \%)$ had no LGE. $^{21}$

This calls for the question: Is there another way to predict SCD in patients with HCM who appear to be at low risk by conventional risk factors? The answer almost certainly involves accurate understanding of the pathologic substrate that produces ventricular arrhythmias in this disease. ${ }^{3}$ This is especially likely when there is no significant myocardial scarring detectable by LGE on MRI. Considerable evidence has accumulated that ischemia and coagulative ischemic necrosis are important contributors to both myocardial fibrosis and the occurrence of SCD in HCM. ${ }^{23-29}$ Autopsy studies have demonstrated intimal and medial thickening of intramyocardial arterioles which limit myocardial perfusion in HCM. ${ }^{24,30-33}$ Along with increased myocardial oxygen demands of hypertrophied myocardium, blunted myocardial blood flow during stress produces ischemia. The increased interstitial fibrosis and reduced capillary density also contribute to ischemia in HCM. Increased levels of serum Troponin I in HCM are further evidence that ischemic injury is an important component of this disease.

Positron emission tomography (PET) with either $\mathrm{O}^{15}$-labeled water or $\mathrm{N}^{13}$-labeled ammonia is the most reliable method for imaging myocardial blood flow (MBF) in HCM. ${ }^{34,35}$ Measurements of MBF by PET at rest and during maximal vasodilation have demonstrated marked limitation of coronary flow reserve in patients with HCM in the absence of epicardial coronary artery disease, offering powerful evidence of microvascular dysfunction. ${ }^{3}$ The relation of reduced MBF reserve and myocardial fibrosis using MRI has been well established in HCM. ${ }^{33-35}$ Indeed, the identification of significantly reduced MBF reserve by PET has been shown to be a powerful predictor of subsequent mortality in HCM. ${ }^{34}$

Bravo has summarized the role of PET for detection of myocardial ischemia in HCM. ${ }^{36}$ The advantages of PET compared with SPECT include superior pharmacokinetic properties, higher spatial resolution of the reconstructed images, and more sensitive detection of radiotracer concentration. If patients with $\mathrm{HCM}$ can be identified as having a significant risk for SCD based on myocardial ischemia by PET imaging even in the absence of traditional risk factors, this tragic outcome may be further reduced. In addition, if PET imaging can be shown to identify a low risk of SCD in patients predicted to be at increased risk with standard risk factors, more patients could be spared the noxious effects of living with an ICD. However, before such an approach can be applied to HCM, prospective trials of PET imaging across the spectrum of this disease will be required. Towards this end there are issues that need to be addressed: (1) Is there an interaction between PET assessment of MBF and traditional risk factor for predicting SCD? (2) Can PET alone provide sufficient evidence for or against ICD implantation? (3) What is the optimal frequency that PET imaging should be performed in HCM patients without an ICD? (4) What is the best method for assessing epicardial coronary artery disease in HCM patients with abnormal perfusion by PET imaging? (5) Is there an interaction between specific genetic mutations underlying $\mathrm{HCM}$ and $\mathrm{MBF}$ assessed by PET imaging?

If these research questions can be answered, PET imaging may have a significant role to play in the management of patients with HCM, whereby patients who are not considered high risk for SCD by traditional clinical assessment might be identified early and protected by implantation of an ICD. In addition, if PET can be shown to attenuate the risk of SCD in the presence of standard risk factors, an ICD may be avoided for some patients with this disease. Both are useful goals.

\section{Disclosure}

The author has no conflict of interest to disclose.

\section{References}

1. Gersh BJ, Maron BJ, Bonow RO, Dearani JA, Fifer MA, Link MS, Naidu SS, Nishimura RA, Ommen SR, Rakowski H, Seidman CE, Towbin JA, Udelson JE, Yancy CW. 2011 ACCF/AHA guideline for the diagnosis and treatment of hypertrophic cardiomyopathy. $\mathrm{J}$ Thorac Cardiovasc Surg 2011;142:153-203.

2. Maron BJ, Maron MS. Contemporary strategies for risk stratification and prevention of sudden death with the implantable defibrillator in hypertrophic cardiomyopathy. Heart Rhythm 2016;13:1155-65.

3. Maron MS, Olivotto I, Maron BJ, Prasad SK, Cecchi F, Udelson JE, Camici PG. The case for myocardial ischemia in hypertrophic cardiomyopathy. J Am Coll Cardiol 2009;54:866-75.

4. Maron BJ, Olivotto I, Spirito P, et al. Epidemiology of hypertrophic cardiomyopathy-related death: Revisited in a large nonreferral-based patient population. Circulation 2000;102:858-64.

5. Maurizi N, Passantino S, Spaziani G, Girolami F, Arretini A, Targetti M, Pollini I, Tomberli A, Pradella S, Calabri GB, Vinattieri V, Bertaccini B, Leone O, De Simone L, Rapezzi C, Marchionni N, Cecchi F, Favilli S, Olivotto I. Long-term outcomes of pediatric-onset hypertrophic cardiomyopathy and agespecific risk factors for lethal arrhythmic events. JAMA Cardiol 2018. https://doi.org/10.1001/jamacardio.2018.0789.

6. Marrakchi S, Kammoun I, Bennour E, Laroussi L, Kachboura S. Risk stratification in hypertrophic cardiomyopathy. Herz 2018. https://doi.org/10.1007/s00059-018-4700-8.

7. Maron BJ, Spirito P, Shen WK, Haas TS, Formisano F, Link MS, Epstein AE, Almquist AK, Daubert JP, Lawrenz T, Boriani G, 
Estes NA 3rd, Favale S, Piccininno M, Winters SL, Santini M, Betocchi S, Arribas F, Sherrid MV, Buja G, Semsarian C, Bruzzi P. Implantable cardioverter-defibrillators and prevention of sudden cardiac death in hypertrophic cardiomyopathy. JAMA 2007;298:405-12.

8. Maron BJ, Casey SA, Olivotto I, Sherrid MV, Semsarian C, Autore C, Ahmed A, Boriani G, Francia P, Winters SL, Giudici M, Koulova A, Garberich R, Rowin EJ, Sears SF, Maron MS, Spirito P. Clinical course and quality of life in high-risk patients with hypertrophic cardiomyopathy and implantable cardioverter-defibrillators. Circ Arrhythm Electrophysiol 2018;11:e005820. https:// doi.org/10.1161/CIRCEP.117.005820.

9. Al-Khatib SM, Stevenson WG, Ackerman MJ, Bryant WJ, Callans DJ, Curtis AB, Deal BJ, Dickfeld T, Field ME, Fonarow GC, Gillis AM, Hlatky MA, Granger CB, Hammill SC, Joglar JA, Kay GN, Matlock DD, Myerburg RJ, Page RL. 2017 AHA/ACC/HRS guideline for management of patients with ventricular arrhythmias and the prevention of sudden cardiac death. J Am Coll Cardiol 2017. https://doi.org/10.1016/j.jacc.2017.10.054.

10. Spirito P, Maron BJ. Relation between extent of left ventricular hypertrophy and occurrence of sudden cardiac death in hypertrophic cardiomyopathy. J Am Coll Cardiol 1990;15:1521-6.

11. Christiaans I, van Engelen K, van Langen IM, et al. Risk stratification for sudden cardiac death in hypertrophic cardiomyopathy: Systematic review of clinical risk markers. Europace 2010;12:31321.

12. Spirito P, Autore C, Rapezzi C, et al. Syncope and risk of sudden death in hypertrophic cardiomyopathy. Circulation 2009;119:1703-10.

13. Viswanathan K, Suszko AM, Das M, et al. Rapid device-detected nonsustained ventricular tachycardia in the risk stratification of hypertrophic cardiomyopathy. Pacing Clin Electrophysiol 2016;39:642-51.

14. Olivotto I, Maron BJ, Montereggi A, et al. Prognostic value of systemic blood pressure response during exercise in a communitybased patient population with hypertrophic cardiomyopathy. J Am Coll Cardiol 1999;33:2044-51.

15. Minami Y, Haruki S, Kanbayashi K, Itani R, Hagiwara N. B-type natriuretic peptide and risk of sudden death in patients with hypertrophic cardiomyopathy. Heart Rhythm 2018. https://doi.org/ 10.1016/j.hrthm.2018.04.030.

16. Sorajja P, Nishimura RA, Ommen SR, et al. Use of echocardiography in patients with hypertrophic cardiomyopathy: Clinical implications of massive hypertrophy. J Am Soc Echocardiogr 2006; 19:788-95.

17. Maron MS, Olivotto I, Betocchi S, et al. Effect of left ventricular outflow tract obstruction on clinical outcome in hypertrophic cardiomyopathy. N Engl J Med 2003;348:295-303.

18. Maron BJ, Rowin EJ, Casey SA, et al. Hypertrophic cardiomyopathy in adulthood associated with low cardiovascular mortality with contemporary management strategies. J Am Coll Cardiol 2015;65:1915-28.

19. Choudhury L, Mahrholdt H, Wagner A, Choi KM, Elliott MD, Klocke FJ, et al. Myocardial scarring in asymptomatic or mildly symptomatic patients with hypertrophic cardiomyopathy. J Am Coll Cardiol 2002;40:2156-64.

20. Bruder O, Wagner A, Jensen CJ, Schneider S, Ong P, Kispert EM, et al. Myocardial scar visualized by cardiovascular magnetic resonance imaging predicts major adverse events in patients with hypertrophic cardiomyopathy. J Am Coll Cardiol 2010;56:875-87.

21. Chan RH, Maron BJ, Olivotto I, Pencina MJ, Assenza GE, Haas T, Lesser JR, Gruner C, Crean AM, Rakowski H, Udelson JE, Rowin
E, Lombardi M, Cecchi F, Tomberli B, Spirito P, Formisano F, Biagini E, Rapezzi C, De Cecco CN, Autore C, Cook EF, Hong SN, Gibson CM, Manning WJ, Appelbaum E, Maron MS. Prognostic value of quantitative contrast-enhanced cardiovascular magnetic resonance for the evaluation of sudden death risk in patients with hypertrophic cardiomyopathy. Circulation 2014;130:484-95.

22. Green JJ, Berger JS, Kramer CM, Salerno M. Prognostic value of late gadolinium enhancement in clinical outcomes for hypertrophic cardiomyopathy. J Am Coll Cardiol Imaging 2012;5:3707.

23. O'Hanlon R, Grasso A, Roughton M, Moon JC, Clark S, Wage R, et al. Prognostic significance of myocardial fibrosis in hypertrophic cardiomyopathy. J Am Coll Cardiol 2010;56:867-74.

24. Maron MS, Appelbaum E, Harrigan CJ, Buros J, Gibson CM, Hanna C, et al. Clinical profile and significance of delayed enhancement in hypertrophic cardiomyopathy. Circulation 2008;1:184-91.

25. Basso C, Thiene G, Corrado D, Buja G, Melacini P, Nava A. Hypertrophic cardiomyopathy and sudden death in the young: Pathologic evidence of myocardial ischemia. Hum Pathol 2000;31:988-98.

26. Dilsizian V, Bonow RO, Epstein SE, Fananapazir L. Myocardial ischemia detected by thallium scintigraphy is frequently related to cardiac arrest and syncope in young patients with hypertrophic cardiomyopathy. J Am Coll Cardiol 1993;22:796-804.

27. Cecchi F, Olivotto I, Gistri R, Lorenzoni R, Chiriatti G, Camici PG. Coronary microvascular dysfunction and prognosis in hypertrophic cardiomyopathy. N Engl J Med 2003;349:1027-35.

28. Lu DY, Yalçin H, Yalçin F, Zhao M, Sivalokanathan S, Valenta I, Tahari A, Pomper MG, Abraham TP, Schindler TH, Abraham MR. Stress myocardial blood flow heterogeneity is a positron emission tomography biomarker of ventricular arrhythmias in patients with hypertrophic cardiomyopathy. Am J Cardiol 2018;121:1081-9.

29. Maron BJ, Epstein SE, Roberts WC. Hypertrophic cardiomyopathy and transmural myocardial infarction without significant atherosclerosis of the extramural coronary arteries. Am J Cardiol 1979;43:1086-102.

30. Maron BJ, Wolfson JK, Epstein SE, Roberts WC. Intramural ("small vessel") coronary artery disease in hypertrophic cardiomyopathy. J Am Coll Cardiol 1986;8:545-57.

31. O'Gorman DJ, Sheridan DJ. Abnormalities of the coronary circulation associated with left ventricular hypertrophy. Clin Sci (Lond) 1991;81:703-13.

32. Roberts WC, Ferrans VJ. Pathologic anatomy of the cardiomyopathies. Idiopathic dilated and hypertrophic types, infiltrative types, and endomyocardial disease with and without eosinophilia. Hum Pathol 1975;6:287-342.

33. Bengel FM, Higuchi T, Javadi MS, Lautamaki R. Cardiac positron emission tomography. J Am Coll Cardiol 2009;54:1-15.

34. Olivotto I, Girolami F, Sciagra R, Ackerman MJ, Sotgia B, Bos $\mathrm{JM}$, et al. Microvascular function is selectively impaired in patients with hypertrophic cardiomyopathy and sarcomere myofilament gene mutations. J Am Coll Cardiol 2011;58:839-48.

35. Castagnoli H, Ferrantini C, Coppini R, Passeri A, Baldini K, Berti $\mathrm{V}$, et al. Role of quantitative myocardial positron emission tomography for risk stratification in patients with hypertrophic cardiomyopathy: A 2016 reappraisal. Eur J Nucl Med Mol Imaging 2016;43:2413-22.

36. Bravo PE. Is there a role for cardiac positron emission tomography in hypertrophic cardiomyopathy? J Nucl Cardiol 2018. 